Proceedings of the International Conference on Teaching, Education and Learning Conference, Vol. 1, 2021, pp. 46-62 Copyright (C) 2021 iConferences

ISSN 2820-2155

DOI: https://doi.org/10.32789/tel.2021.1004

\title{
Grade 8 Students’ Level of Conceptual Understanding of Electric Circuits Using Virtual Manipulative
}

Jesserene P. Bantolo ${ }^{1}$, Dr. Voltaire M. Mistades ${ }^{2}$

${ }^{1}$ Mapúa University, Philippines, jesserene.prodigalidad@gmail.com

${ }^{2}$ De La Salle University, Philippines, voltaire.mistades@dlsu.edu.ph 


\title{
GRADE 8 STUDENTS’ LEVEL OF CONCEPTUAL UNDERSTANDING OF ELECTRIC CIRCUITS USING VIRTUAL MANIPULATIVE
}

\begin{abstract}
The challenge to Physics teachers is finding ways to address students' alternative conceptions and misconceptions. Traditional instruction often fails to change these ideas because students deeply hold them. In this study, we report the effects of using virtual manipulatives on students' conceptual understanding of the topic, electricity. In learning the concepts on DC circuits, energy, current-voltage-resistance relationship, and potential difference, the students used the Physics Education Technology (PhET) interactive simulations project of the University of Colorado, particularly the Circuit Construction Kit DC Virtual Lab simulation app. The virtual activities that the students conducted were able to augment the class discussion. The results of the post-instruction administration of the assessment instrument, Determining and Interpreting Resistive Electric Circuits Test (DIRECT), revealed that the simulations helped the students analyze the physical aspects of electric circuits. Technology integration in classroom discussion of electric circuits effectively engaged students to learn more about Physics concepts.
\end{abstract}

Keywords: Conceptual understanding, electric circuits, virtual manipulatives, interactive simulations

\section{Introduction}

The Philippine education system had undergone too many changes through time. It follows the same pattern of curriculum development and reform practices as other countries (Cruz, 2003). These transformations were also caused by the disadvantaged position of the country in international assessment in education. According to the report cited by Orleans (2007), the Philippines was placed in a disadvantaged position among participating nations in Second International Science Study (SISS) and Third International Mathematics and Science Study (TIMSS). The two mentioned studies were conducted primarily to assess the secondary education of the Philippines. This status shows that Filipino secondary students lack international standards, particularly in Math and Science.

As part of the dynamic discipline, Science is one of the subjects that undergo a major revision in the Enhance Basic Education 2013 (Montebon, 2014). The Department of Education (DepEd) allowed this innovation to construct an enhanced Basic Education curriculum that will satisfy the demand of 21st-century workers of today's generation.

The Republic Act of 1033, also known as Enhanced Basic Education Curriculum of 2013, was introduced in the academic year 2012-2013. This new Basic Education Curriculum is tied up with the new trend of ASEAN countries that extend basic education for two more years, called Senior High School. From this, the grade 7 to 10 curriculum was changed, which drastically targeted numerous disciplines, including Science. Montebon (2014) stated that the new science program has many innovations and two of which the competencies were congested and its arrangement in a spiral progression manner. Congestion of competencies means that a specific competency that would take up to 3 weeks to cover will become 1 or 2 weeks because other 
competencies will be discussed in time for the quarter assessment. Meanwhile, the spiral curriculum has been practiced in western countries, making it more appealing to the Philippine Department of Education (DepEd) to align our system in that concept. However, the spiral curriculum also provides benefits, according to the advocators. It allows a logical progression from simple to complicated ideas (Johnston, 2012). He also highlighted that Bruner's spiral curriculum empowers students' stock knowledge each time the student revisits the subject matter.

Despite the benefit ascribed by the advocators to spiral curriculum, administrators cannot deny that following this curriculum will shift the science program into a whole new set-up. Teachers need to undergo a series of training to practice inquiry-based learning, unpacking the educators' TPACK (Technological Pedagogical Content Knowledge), which was the most advisable pedagogy for this new curriculum. Looking at the bigger picture, science educators lack skills and training since most of the teachers were a product of the Basic Education Curriculum (BEC). In addition, the implementation of this new curriculum raised many concerns from different sectors of the society (Montebon, 2014). The research tended to focus on how we can alleviate the current situation of education in the Philippines with these changes in the curriculum.

Science program under the K-12 curriculum envisions the learners to develop scientific literacy that will prepare them to be well informed and participative citizens who are able to make judgements and decisions with regards to the applications of scientific knowledge that may have social, health, or environmental impacts (DepEd, 2018). For the 21st-century teaching strategy, the use of technology has been abundant in school as the primary material needed by the teacher. Many universities have supported open education in the past years, wherein students can enroll and study the modules asynchronously to finish their chosen degree. Another breakthrough in education was the use of simulations which was also known as the virtual manipulation teaching technique, and it is widely accepted in education. These innovations and alternative solutions can be done by utilizing computer technology (Gunawan et al., 2017). It allows the student to fill the gaps of laboratory experiments as it showcases experimental function in a laboratory to be performed on a computer. It can provide better quality software, increase pedagogy choice, and enhance flexibility. This research aims to study the benefit of teaching techniques ascribed in conceptual change through this innovation in education. The central issue that this paper addressed is the use of virtual manipulation to increase students' conceptual understanding of physics concepts. It aims to expand the use of virtual manipulation in Physics class instead of the traditional laboratory set up in class. More specifically, this research aims to answer the following question:

1. Prior to instruction, what concepts about electricity do students hold?

2. After instruction, is there a significant difference in the gain score of students?

3. What were conceptual understandings reflected in the student's post-test scores? 
The questions presented are the framework of the treatment used during the study. The gain score presented in the results showcased the effect of virtual manipulation treatment in the study.

\section{Conceptual Framework}

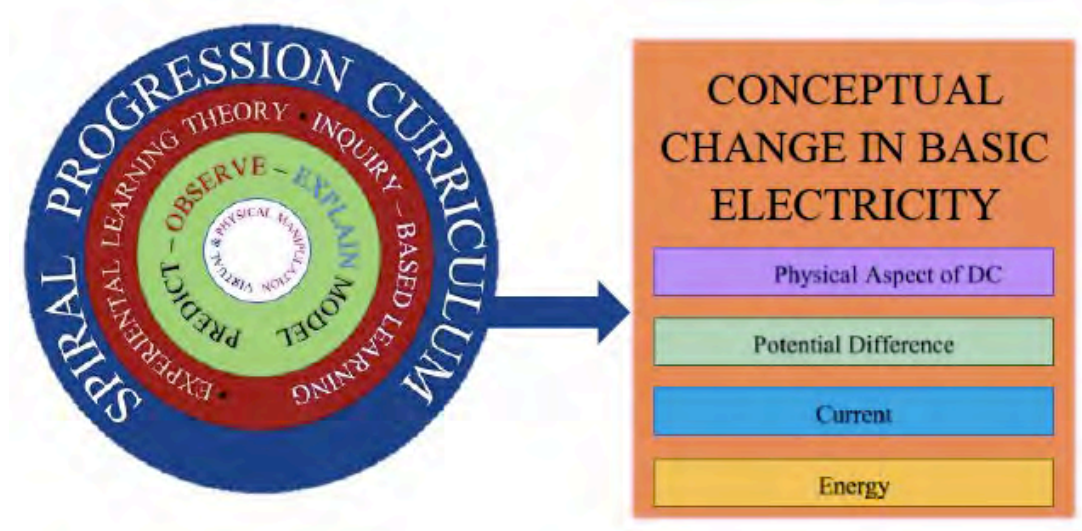

Figure 1. Conceptual framework of the study

Through the spiral progression of Burner, which was reported in the paper of Johnston (2012), the Department of Education (DepEd) identified eight (8) pedagogies that theoretically support the $\mathrm{K}$ - 12 curriculum. DepEd's rationale behind K-12's profound change in the curriculum is due to the demand of other countries with 12-year basic education programs. Robust education will form throughout the 12 years in basic education since the program will align with international practices. Based on the World Bank Philippines Skills Report 2009, the Philippines recommend adding two more years to basic education (Visconde, 2015). These additional years in basic education increases the chance of getting a job after high school, and Filipino student can compete outside the country. Despite the vision mentioned in the framework of $\mathrm{K}-12$, specifically in Science program released last 2011, many educators from higher education institutions raised their concerns regarding teacher's training, lack of implementing guidelines, insufficient resources of implementation, and others. Abdul \& Akhilesh (2010) mentioned that these factors were the reason why teachers' teaching in basic education must address children's science concepts with careful consideration while planning the teaching strategy

Planning the lesson and instructional material to be used is one example of conceptualizing their pre-conception to the topic. All students are experiencing science in their day-to-day lives that enables them to strongly hold their beliefs and expectations (Abdul \& Akhilesh, 2010). In line with their pre-conception, students still accept the teacher's "science" for the duration of the topic being discussed inside the classroom and return to their intuitive ideas following the instruction. As learned misconceptions and pre-conceptions may arise as barriers in learning, replacing them with scientific ones is possible only through conceptual change (Abdul \& 
Akhilesh, 2010). Therefore, an effective pedagogy or learning model will be one of the strategies educators should practice to achieve a proper transition of conceptual change.

Inquiry-based learning or IBL is one of the known pedagogies that most teachers, textbook writers, and school administrators are using nowadays. It is an active learning model in which students are given a carefully scaffolded sequence of tasks and are asked to solve and make sense of them (Ernst, Hogde, \& Yoshinobu, 2018). From this, virtual manipulation as a teaching technique takes place. Active learning for the 21st century is making use of technology as one of the platforms in teaching. It opens the diverse culture of the students that can easily adapt to change. Kolb, Doyatzis, \& Mainemelis (1999) emphasized the idea of experiential learning theory, which is defined as the process where knowledge is created through the transformation of experience. In the impression made by Kolb, D. et al. (1999), they define two modes, Concrete Experience (CE) and Abstract Experience (AE). As the students learn through simulation with the use of virtual manipulation teaching technique, they experience $\mathrm{CE}$ by observing the ideas made through simulation, and these reflections are assimilated and distilled into abstract concepts from which the new implication can be drawn out by the students (Kolb et al., 1999). In Abstract Experience, students tend to analyze and systematically plan the next step to learn the lesson well, apply it in the real world while using virtual manipulation.

Science instruction was done best using demonstrations. This technique allows immediate response and feedback from the students, especially in a complex concept in science. The Predict-Observe-Explain (POE) model of White and Gunstone (1992) creates a condition for students to use their initial ideas prior to the instruction and explore the concept afterward. This model is widely accepted under the constructivist approach.

\section{Significance of the Study}

The research study provided educators with an effective teaching technique that follows the DepEd prescribed pedagogy without eliminating students' learning capacity. It considered students' prior knowledge of the concept and gathered the misconception that will also help the teacher create appropriate instructions for conceptual change. This research will also help school administrators provide training to non-physics major teachers who are teaching physics in the spiral curriculum approach of the K-12 Program. At the same time, it will add to research that focuses on the advantage of virtual manipulation as teaching techniques and conceptual understanding through conceptual change. Therefore, it will boost the literature on virtual manipulation, which will help educators know the benefit of this teaching technique.

\section{Research Methodology}

The participants for this research were grade 8 students from a private school in Bacoor, Cavite, Philippines. Students were composed of good numbers of old students, and only $10 \%$ of the sample are transferees. They were sectioned heterogeneously; it only showed that they were assigned to their respective section without any reservation or factors to consider. Participants also had their elective class in Grade 7, which is a science-based subject. Basic Electronics was their elective class that most 
likely would help the student form a good pre-conception to the topic discussed during the implementation. Thirty (30) of the participants were male, and thirty-two (32) were female, with a total of sixty - two 62 participants for this study.

\section{Instrumentation}

Determining and Interpreting Resistive Electric Circuits and Concept Test Version 1.2 or DIRECT of Engelhardt and Beichner (2004) is a twenty-nine (29) multiple-choice questionnaire used to tease out students' misconceptions on electric circuit topics. This inventory test has a good reliability and validity result as this was tested among 1135 students, 681 at university level and 454 at high school level (Engelhardt \& Beichner, 2004). For this research, the researcher used the instrument to evaluate the student's progress in learning concepts with virtual and physical manipulation treatment intervention. The effectiveness of the teaching techniques was determined by the changes in pre and post-test scores during the two-week implementation if the teaching technique being studied reveals students' conceptual change; retention test is also facilitated 3 months after the post-test to check the level of conceptual change. Low scored items were referred to as the misconception of the student in the pre-test. Students used scannable answers sheet provided by the researcher. The instrument was given on the first day of the first two weeks of data gathering. The pre-testing of DIRECT helped the researcher to know the misconceptions of students about the topics. The post-test score facilitated the level of conceptual change in the topic provided with the treatment of teaching techniques for the group.

\section{Data Collection}

The researcher introduced the content to the students by giving them background lectures about electricity. On the other hand, the teacher facilitated the pre-instruction of DIRECT to the student. Announcement of the scores was done 2 days after the examination for protocol purposes. Unannounced pre-testing was designed to help the researcher in acquiring accurate data for students' misconceptions. Through the data in the pre-test score and low areas in DIRECT, the researcher used this to analyze which area to focus more on the activities and discussion. The DIRECT assessment was coined as the "Electricity Concept Survey Test" to prevent the student from looking up the answers to the question on the internet. Additional to the DIRECT questionnaire, the researcher provided sets of the question for their demographic profiling. This additional information like their sex, computer familiarity, and years of stay in the school helped the researcher conceptualize the level of conceptual change.

Virtual Manipulation (VM) group had their one-day orientation about the use of simulation. In this orientation, students had their background orientation and user interface familiarity with the simulation. Instructions for the use of Google Classroom during the lesson were discussed in the said orientation.

The researcher helped the students to assess themselves in the teaching technique to be used by having a tutorial lesson on how to use simulation properly. The tutorial served as supplementary material for the students throughout the lesson. During the implementation of the treatment, the students utilized 
both classroom and computer laboratory for the assistance of the teaching technique. Probing technique was used during the discussion and simulation.

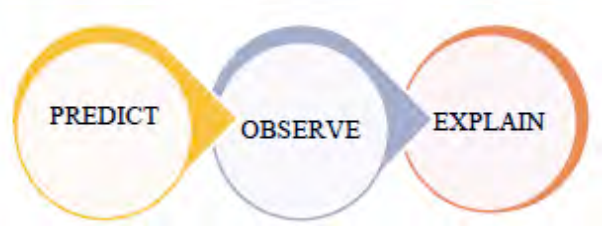

Figure 2. P-O-E Model

Figure 2 depicts how the learners' understanding develops from an interactive discussion (Zacharia, 2005). Students have more "think time" when using this technique. It helped the researcher analyze whether the students have misconceptions regarding the topic and address it immediately with the pedagogy used in that learning episode.

Throughout the two-week implementation, the researcher used Physics Education Technology (PhET) Interactive Simulation, a project at the University of Colorado Boulder. This free interactive simulation is user-friendly and has a great number of computer simulations in different science fields. The researcher used the Circuit Construction Kit: DC - Virtual Lab simulation to treat the virtual group. It was accompanied by discussion in a regular classroom set-up or while using the simulation.

After the two-week implementation, the researcher administered the post-test of DIRECT to the students. This posttest determined the effectiveness of teaching techniques if a conceptual change occurs in the two-week implementation using Gain Score Test and the item analysis to show the data for conceptual change.

At the end of the quarter, the researcher facilitated a retention test. This assessment measured the amount of retained concepts and evaluated the level of conceptual change acquired. It managed the period of transition that may have a significant impact on the students (Mathys, Veronneau, \& Lecocq, 2019). The review conducted by Singer et al. (2006) on 37 studies as cited by Bahrami et al. (2012) indicated that, compared to individual learning, cooperative learning not only improves the attitude of students but also enhances their retention. 


\section{Research Findings}

Table 1: Prior knowledge of the students

$\begin{array}{lll}\text { QUESTION } & \text { OBJECTIVE } & \text { LEARNING AREA } \\ \text { NUMBER } & \text { NUMBER }\end{array}$

18 The physical aspect of DC electric circuits

$22 \quad$ The physical aspect of DC electric circuits

$27 \quad$ The physical aspect of DC electric circuits

$16 \quad 10 \quad$ Potential difference

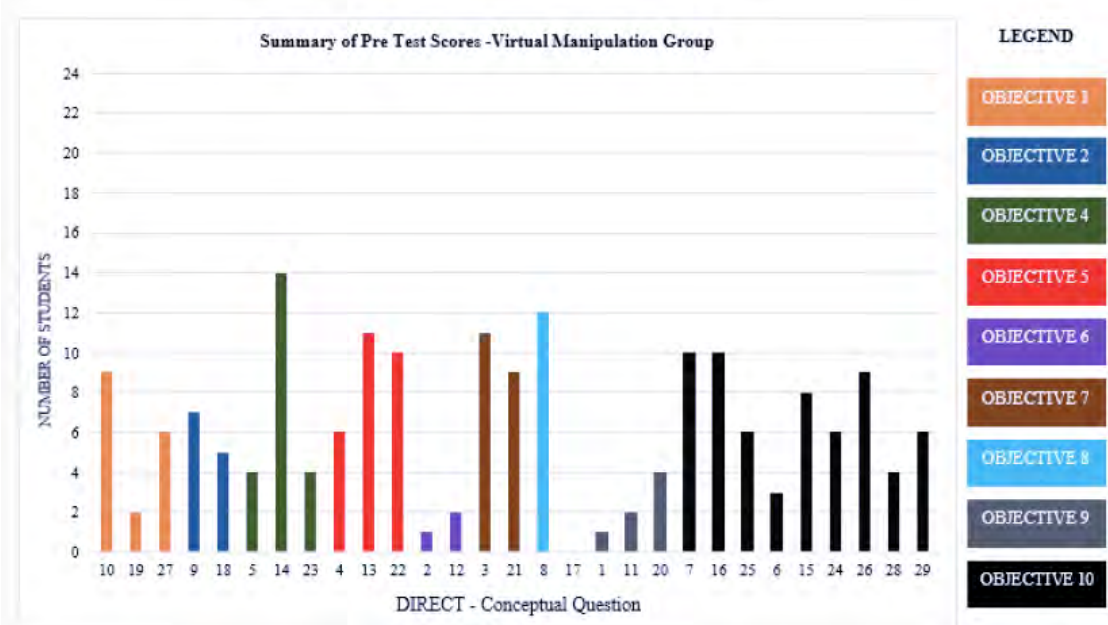

Figure 3. Summary of Pre-test Scores

Figure 3 shows the pre-test scores of the VM group. The group accumulated an average group score of 6.27. According to the presented data, questions number 14, 8, 13, and 3 got the highest score from the assessment prior to the instruction. Students from this group accumulated the highest score in question number 14 under objective 4 of the DIRECT assessment. The question focused on the total resistance of the given series-parallel connection of resistors. Students tend to use their prior knowledge about the flow of electricity in a household since the question used a familiar term like "switch is closed." Another question that got the highest score in the DIRECT assessment is question number 8 . This question focused on the comparison of current in two points in a series connection. The choices provided in question number 8 follow only $50 \%$ of the chances of getting the correct answer since two (2) of the given choices point to the same thought based on the diagram in the question. It provided the students with a good context clue in getting the correct answer. Question numbers 3 and 13 got the 
same score in the assessment. Both questions used a diagram as an option that helped the student to determine the correct answer. Using familiar words like "energy" also increases the chance of getting the correct answer. Question number 13 used a realistic series-parallel circuit with a battery, making the question more familiar to the student.

Based on the data shown in table 1, students showed an increase in learning that describes the effectiveness of teaching techniques. The simulation used for the group helped the students grasp the idea of correct circuiting.

Following the model of conceptual change espoused by (Hewson 1992). This study used the category below in describing the types of conceptual change.

Table 2 shows the identified 4 categories in analyzing the conceptual change persist by the group using the pretest and posttest scores. The category is based on the nature of the given answer in pretest or posttest, identified as correct and wrong.

Table 2: Category of Conceptual Change

CATEGORY OF CONCEPTION

Wrong to wrong

Wrong to correct

Correct to correct

Correct to wrong
TYPE OF CONCEPTUAL CHANGE

Negative

Positive

No conceptual change

Negative 


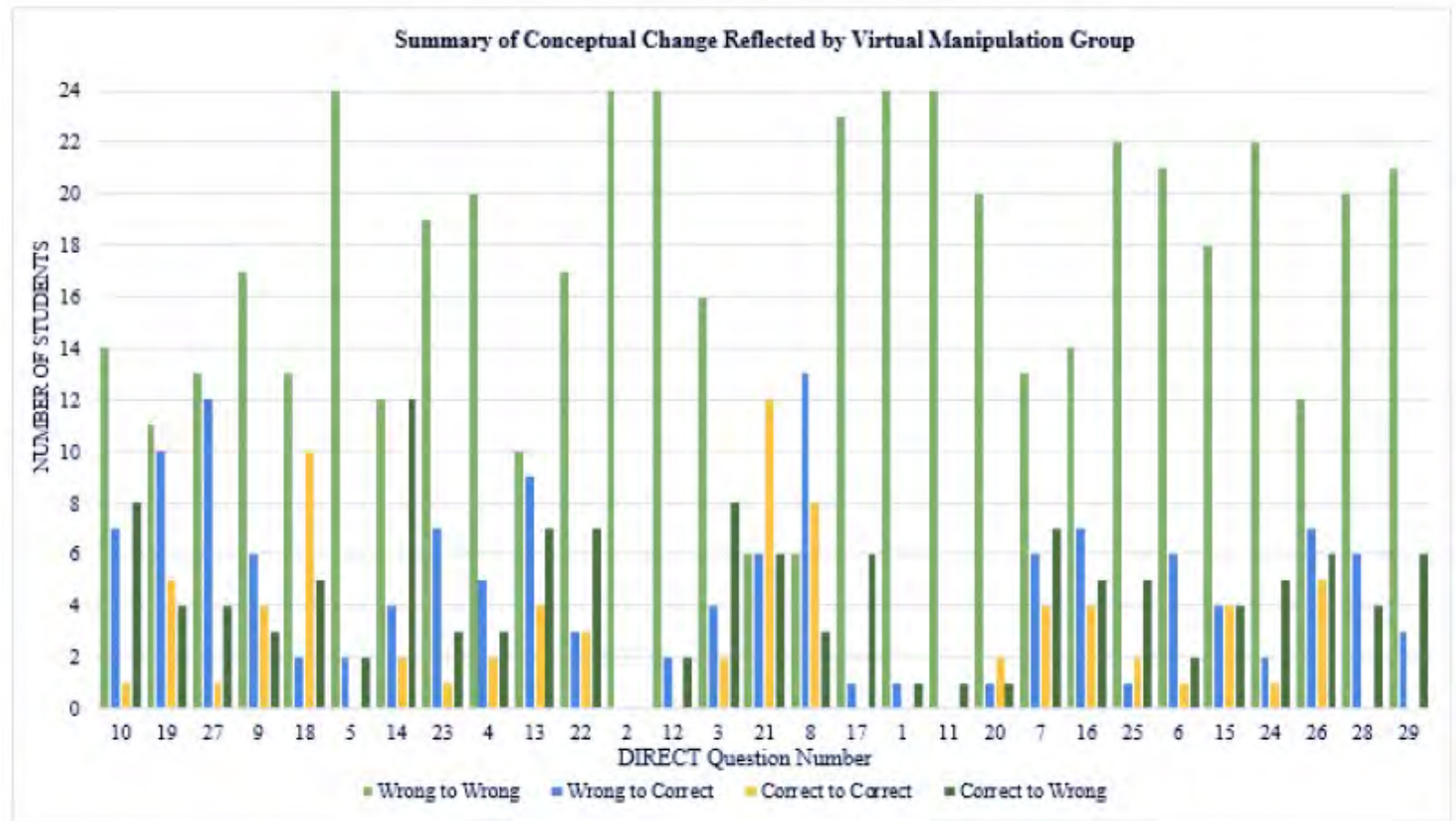

Figure 4. Conceptual Change Reflected by Virtual Manipulation Group

Figure 4 revealed the conceptual change manifested by the Virtual Manipulation (VM) group after the treatment made using Physics Education Technology (PhET) simulator. The individual answers for the pre-test and post-test of the VM group have been analyzed and grouped into 4 categories: wrong to wrong, wrong to correct, correct to correct, and correct to wrong. This category was assigned based on their answer from pre-test to post-test, respectively. The researcher assigned this category to identify the conceptual change of each group.

Based on the analyzed data, the VM group has an evident number of wrong-to-wrong conception after the instruction. According to the data, question number 2 has the highest number of students with identified "strong misconception" (Sadler \& Sonnert, 2016), also recognized as negative conceptual change. The objective of the question is to apply the concept of power to series and parallel circuits. Students need to use their prior knowledge about power to answer question number 2 . The question tends to be more difficult to answer since the given question requires pre-conception regarding power. The pre-requisite topic is not part of grade 7 physics based on the curriculum guide provided by the Department of Education (DepEd) in the Philippines. In addition, the content tested was not covered during the two-week implementation.

On the contrary, the students showed a wrong to correct conception after the treatment, which is evident in the figure above. Question number 8 has the highest value of wrong to positive conception. This conceptual change was identified as a positive conceptual change. Students were able to differentiate the correct answer from the distractor in the question. The question's objective is to understand and apply the idea of conservation of current to a variety of circuits. This test question used 
the series connection of the light bulb to the battery, strengthening the chance to understand the concept of the question. Students thought that the simpler the circuit is, the better it is to understand. This conclusion was based on the researcher's initial classroom observation during the implementation. The concept behind the question is simple and easier to understand; the given distractor is also easier to differentiate from the correct answer. The two points given from the figure in the question are strong accounts in getting the correct answer.

The table below is presented to determine the significant difference in the gain score that predicted the conceptual change.

Table 3: Gain Score

TEACHING TECHNIQUE PRETEST(\%) POSTTEST(\%) GAIN SCORE

$\begin{array}{llll}\text { Virtual Manipulation } & 21.17 & 23.04 & 0.03\end{array}$

The average score gained of the VM group is 0.03 . However, quantitatively speaking, this number reflects less than $1(<1)$ percent gain score. It only indicates that there is only a small amount of positive gained. Another thing to consider from the given gain score is the value of the highest positive and negative individual gain score. Even though it does not reflect the whole group, it has significance based on its value. The highest negative gain score is 7 , while the highest positive gain is 8 . As Cohen et al. (2003) stated, the gain score can often overcorrect the post-test by the pre-test, but the interpretation depends on our theoretical model of change. In this paper, the theoretical model of change refers to the effectiveness of the teaching technique in creating conceptual change. Virtual manipulation of a teaching technique applied in this study showed a small value of positive gain and negative gain. It only shows that there are only small infractions from which the group can comprehend conceptual change using the virtual manipulation teaching technique.

Table 4: Retention Gain Score.

\begin{tabular}{llll} 
TEACHING TECHNIQUE & PRETEST(\%) & $\begin{array}{l}\text { DELAYED } \\
\text { POSTTEST (\%) }\end{array}$ & $\begin{array}{l}\text { RETENTION GCORE } \\
\text { SCOIN }\end{array}$ \\
\hline Virtual Manipulation & 21.17 & 25.81 & 0.05 \\
\hline
\end{tabular}

Table 4 depicts the retention gain score of the group. As shown in the table, there is an increase in the scores in the delayed posttest. A gain score of 0.05 is recorded through the analysis. It describes that the concepts retained from the discussion. It is also helpful that the researcher supplies necessary remediation during the post-implementation and provides supplementary material for the topic. 
Table 5: List of Common Conception of Virtual Manipulation Group

\begin{tabular}{|c|c|c|c|}
\hline $\begin{array}{l}\text { OBJECTIVE } \\
\text { NUMBER }\end{array}$ & $\begin{array}{l}\text { QUESTION } \\
\text { NUMBER IN } \\
\text { DIRECT }\end{array}$ & OBJECTIVE & $\begin{array}{l}\text { COMMON } \\
\text { CONCEPTION }\end{array}$ \\
\hline 8 & 8 & $\begin{array}{l}\text { Understand and apply } \\
\text { conservation of current } \\
\text { (conservation of change in } \\
\text { a steady state) to a variety } \\
\text { of circuits. }\end{array}$ & $\begin{array}{l}\text { The current (I) } \\
\text { possessed by a series } \\
\text { connection is equal } \\
\text { throughout the circuit. }\end{array}$ \\
\hline 5 & 13 & $\begin{array}{l}\text { Interpret pictures and } \\
\text { diagrams of various } \\
\text { circuits, including series, } \\
\text { parallel, and combinations } \\
\text { of the two. }\end{array}$ & $\begin{array}{l}\text { Series connection is } \\
\text { always connected in a } \\
\text { single path, while the } \\
\text { parallel is always } \\
\text { connected separately. }\end{array}$ \\
\hline 1 & 19,27 & $\begin{array}{l}\text { Identify and explain a } \\
\text { short circuit. }\end{array}$ & $\begin{array}{l}\text { A series connection has } \\
\text { the same current } \\
\text { throughout the circuit; } \\
\text { therefore, all the bulbs } \\
\text { connected in series will } \\
\text { have the same } \\
\text { brightness. }\end{array}$ \\
\hline
\end{tabular}

Apply the concept of The resistance of the resistance (the hindrance circuit serves to limit to the flow of charges in a the amount of current circuit), including that through the circuit with resistance is a property of a given amount of the object (geometry of voltage supplied by the object and type of material battery if the circuit is with which the object is closed. composed) and that in series, the resistance increases as more elements are added. In parallel, the resistance decreases as more elements are added. 
Understand the functional The electrical foot two-ended circuit contact and the screw elements. thread should be connected on the different sides of the battery.

Identify a complete circuit The electrical foot
and understand the contact and the screw
necessity of a complete thread should be
circuit for current to flow connected on the
in the steady-state (some different sides of the
charges are in motion, but battery.
their velocities at any
location are not changing,
and there is no excess
charge accumulation
anywhere in the circuit).

In general, the virtual manipulation group holds a strong misconception in all the content of the DIRECT assessment. One evident factor seen during the implementation is the short period to discuss the content. Congestion of competency in electromagnetism for Science 8 curriculum leads to poor performance of the treated group with virtual manipulation teaching strategy. The DIRECT assessment used general knowledge questions, which consist of general topics about electromagnetism concepts that have an accepted value of validity and reliability for high school and college physics classes. It was also observed that the students could not handle simultaneous changes of variables in circuitry (Engelhardt and Beichner, 2004) during the discussion.

Table 5 depicted the common conceptions held by the Virtual Manipulation group based on their highest scores in positive gain, which refers to wrong to correct conception. Based on the highestranked objectives, the group excelled on questions that tend to ask the complexity of the circuit based on its electron flow. The Circuit Construction Kit, which the virtual treatment of the group has tackled the electron flow in the variety of circuits that helped the respondent answer questions regarding the application of electron flow to the different factors. 


\section{Conclusion}

Based on the findings of this study, it has been shown that the respondents of both groups exhibited positive conceptual change throughout the implementation. Out of 11 objectives of the DIRECT assessment, the VM group performed positive conceptual change in 9 of the objectives. The participants showed differences in the focus where they had their positive conceptual change. The virtual Manipulation (VM) group performed well in analyzing the circuit's physical aspect based on the learning areas set by DIRECT.

In conclusion, Virtual Manipulation can produce positive conceptual change provided with proper materials and guidance from the teacher. The use of Predict - Observe - Explain model is effective to use in probing the conceptions held by the students, which can help identify their misconceptions. With the help of technology and the proper use of traditional teaching techniques, educators can produce conceptual change among the students.

\section{Pedagogical Implication}

This study addressed the different learning styles of the students. Teachers must be equipped with proper training to implement these effectively. Students nowadays are technology-dependent learners. In that case, teachers who incorporate advanced technology in their discussion can effectively engage the students to learn more about physics. The new knowledge brought to them must be linked with their previous knowledge so that the students will be able to accommodate the change. These changes can override the misconception and increase the correct concept. The intensity of the intervention would also be important because aiming for conceptual change to the students that have been used for years will be a challenging task. The intervention must be strong enough and useful to make the students accept the change. Through intervention, teachers would be able to test different teaching strategies that would be most effective for the students. These teaching strategies should be based on the existing learning of the students so that a connection may be established between the old and new learnings. Once the connection is established, providing new concepts would be easier, and the teacher would become more efficient.

Vertical progression of the basic electricity concept is also advised in this study. The researcher had a hard time explaining the simple concept to the student since this is the only grade level they encountered the topic aside from having it as an elective subject when they were in grade 7 in the same school. This vertical progression will help the student nurture the topic from grade 7 to grade 10, with simple to complex ideas across the junior high school science. It will help the teacher to explain the different topics in proper phasing because of their preconception on the said topic.

\section{Acknowledgements}

I want to express my deep and sincerest gratitude to my research adviser, Dr. Voltaire Mistades, for giving me the opportunity to do this research and invaluable guidance throughout. He has taught me to be a research enthusiast. It was a great privilege working and studying under his guidance. 
To my caring and supportive mother, Andrea; and J.A who believes and encourages me to be the best version of myself.

This paper is for you.

\section{References}

Bahrami, F. et al. (2012). A Comparison of the Effectiveness of Game-Based and Traditional Teaching on Learning and Retention of First Grade Math Concepts. European Journal of Experimental Biology, 2099 - 2102.

Balensky, D.M \& Schalk, L. (2014). The Effect of Idealized and Grounded Materials on Learning, Transfer, and Interest: An Organizing Framework for Categorizing External Knowledge Representation. Educational Psychology Review, 27 - 50.

Baser, M. (2006, December 5). Effects of Conceptual Change and Traditional Confirmatory Simulations on PreService Teacher's Understanding of Direct Current Circuits. Journal of Science Education and Technology, 15, 367-381. Doi: 10.1007/s10956-006-9025-3

Braithwaite, D.W., \& Goldstone, R. L. (2015). Effects of Variation and Prior Knowledge on Abstract Concept Learning. Cognition and Instruction, 226 - 256.

Burila, J. (2014). K to 12 Education in the Philippines: For better or for worse? Manila: Academia.edu.

Chiu, M. \& Lin, J. (2005). Promoting fourth graders' conceptual change of their understanding of electric current via multiple analogies. Journal of Research in Science Teaching, 429 - 464.

Chiu, M. and Lin, J. (2005). Promoting fourth graders' conceptual change of their understading of electric current via multiple analogies. Journal of Research in Science Teaching, 429-464.

Cruz, I. (2003). The Basic Education Curriculym in 17 easy lessons. Pasig City, Philippines: Anvil Publishing, Inc.

DepEd. (2018, 05 25). K to 12 Curriculum Guide - SCIENCE. Retrieved from DepEd website: www.deped.gov.ph

Engelhardt, P. and Beichner, R. (2004). Students understanding of direct current resistive electrical forces. Americal Journal of Physics, 98 - 115.

Ernst, D., Hogde, A., and Yoshinobu, S. . (2018). what is inquiry based learning? Doceamus, 570 - 573.

Evans, J. (1978). Teaching electricity with batteries and bulbs. . The Physics Teacher, 15 - 22.

Gafoof, A.K \& Akhilesh, P.T. (2010). Strategies for Facilitating Conceptual Change in School Physics. Innovations and Researches in Education, 3, 34 - 42.

Gardner, H. (1983). Frames of mind: the theory multiple intelligences basic books. Cambridge.

Gilmore, T., Krantz, J., \& Ramirez, R. (Fall, 1986). Action Based Modes of Inquiry and the Host-Researcher Relationship. Consultacion 5.3, 161.

Glover, I. (2014, July 23). Simulation: An Approach to Teaching and Learning. (Sheffield Hallam University) Retrieved January 6, 2019, from Technology Enhanced Learning at SHU: https://blogs.shu.ac.uk/shutel/2014/07/23/simulation-an-approach-to-teaching-and-learning/ 
Goldhaber, D. a. (2003, 5 25). Teacher quality and student achievement. Urban Diversity Series. US Department of Education. New York City: Educational Resources Information Center. Retrieved 05 25, 2018, from ERIC: https://files.eric.ed.gov/fulltext/ED477271.pdf

Gunawan, Harjono, Sahidu, \& Herayanti. (2017). Virtual Laboratory to Improve Students’ Problem - Solving Skills on Electricity Concept. Jurnal Pendidikan IPA Indonesia, 257 - 264.

Hentenes, D. (1987). A modelling theory of physics instruction. Americal Journal of Physics, 440 - 454.

Hewson, P. (1992). Conceptual Change in Science Teaching and Teacher Education. Madrin Spain: National Center for Educational Research, Documentation, and Assessment.

Irrera, D. (2016, May 26). The Use of Simulations as Teaching Tool. Retrieved January 6, 2019, from EInternaltion Relations: https://www.e-ir.info/2016/05/26/the-use-of-simulations-as-a-teaching-tool/

Johnston, H. (2012, March). Education Partnership Inc. Retrieved from Education Partnership Inc. website: www.educationpartnerships.org

Kirschner, P., and Huisman, W. . . (1998). Dry Laboratories in Science Education; Computer based practical work. International Journal of Science Education, 665 - 682.

Kohl, P. and Finkelstein, N. (2006). Effects of representation on student solving physics problems: A finegrained characterization. . Physical Review - Physics Education Research, 010106-1 - 010106-12.

Kolb, D.A, Boyatzis, R., and Mainemelis, C. (1999). Experiential Learning Theory: Previous Research and New Directions. 1 - 25.

Kuphaldt, T. (n.d.). Lessons in Electric Circuit. (Vol. 1). Retrieved June 18, 2018, from http://www.ibiblio.org/kuphaldt/

Liu, T.C., Lin, Y.C, \& Paas, F. (2014). Effects of prior knowledge on learning from different compositions of representations in a mobile learning environment. Computers and Education, 328 - 338.

Mathys, C., Veronneau, M.H., \& Lecocq, A. (2019). Grade Retention at the Transition to Secondary School: Using Propensity Score Matching to Identify Consequences on Pyschosocial Adjustment. Journal of Early Adolesence, 1 - 37. Doi: 10.1177/0272431617735651

McDermott, L., \& Van Zee, E. (1985). Identifying and addressing student difficulties with electric circuits. Ludwidsburg: Walters, R., \& Rhoneck, C. (Eds).

Montebon, D. (2014, December 12). K12 Science Program in the Philippines: Student Perception on its Implementation. International Journal of Education and Research, 2(12), 153 - 164.

Mustafa, B. (2006). Effects of Conceptual Change and Traditional Confirmatory Simulations on Pre-Service Teachers' Understanding of Direct Current Circuit. Journal of Science Education and Technology, 367 - 381.

Orleans, A. V. (2007). The Condition of Secondary School Physics Education in the Philippines: Recent Developments and Remaining Challenges for Substantive Improvements. The Australian Educational Researchers, 33 - 54.

Osborne, R. (2005). Towards modifying children's idea about electric current. Research in Science and Technology Education. 71 - 80.

Palomar, B. (2009). Epistemological Basis of High School Misconceptions' in DC Circuit. De La Salle University, Manila: Master's Thesis. Unpublished. 
Palomar, B. (2014). Science and Non - Science Education Students’ Images and Epistemological Belief towards Physics Learning. The 2nd International History, Philosophy and Science Teaching Asian Regional Conference. Manila: Philippine Normal University.

Philippine Basic Education. (2014, March 27). Philippine Basic Education. Retrieved January 6, 2019, from https://www.philippinesbasiceducation.us/2014/03/philippines-deped-seriously-lacks.html

Posner, G. J. (1982). Accommodation of a scientific conception: Toward a theory of conceptual change. Science Education, 66, 211-227.

Redish, E. (2003). Teaching Physics with Physics Suite. New York City: John Wiley \& Sons, Inc.

Regalado, J. (2009). Students' Conceptions of Direct Current (Unpublished master's thesis). De La Salle University, 3- 4.

Sadler, P. M \& Sonnert, G. (2016). Understanding Misconception. Teaching and Learning in Middle School Physical Science. American Educator, 26 - 32.

Saputro, D.E., Sarwanto, S., Sukarmin, S., \& Ratnasari, D. (2018). Students’ Conception Analysis on Several Electricity Concepts. Journal of Physics: Conference Series, 1-8. doi:10.1088/1742-6596/1013/1/012043

Shipstone, D. M. (1984). A study of childrens' understanding of electricity in simple DC circuit. European Journal of Science Education. 185 - 198.

Singer, D.G., Gollonkoff, R.M., Hirsh-Pasek, K. (2006). New York: Oxford University Press.

Taslidere, E. (2013). Effects of Conceptual Change Oriented Intruction on Students' Conceptual Understanding and Decreasing their Misconceptions in DC Electric Circuit. Creative Education, 273 - 281. doi:10.4236/ce.2013.44041

Thompson, F., and Logue, S. (2006). An Exploration of Common Student Misconceptions in Science. International Education Journal, 553 - 559.

Tsai, C. C. (2003). Using conflict map as an instructional tool to change student alternative conceptions in simple series electric-circuits. Bristish Journal of Educational Technology, 307 - 327.

Visconde, C. D. (2015). Issues, concerns, prospects: teacher training institutions' views on K-12. Luz y Saber. Retrieved November 11, 2018, from https://ejournals.ph/article.php?id=9806

Zacharia, Z. (2005). The Impact of Interactive Computer Simulations on the Nature and Quality of Postgraduate Science Teachers Explanation in Physics. International Journal of Science Education, 1741 -1767.

Zacharia, Z.C., and Anderson, O.R. (2003). The Effects of an Interactive Computer-Based Simulation Prior to Performing Laboratory Inquiry-Based Experiments on Student's Conceptual Understanding of Physics. American Journal of Physics, 618 - 629. 